\title{
TRANSMISIBILIDAD Y DISPONIBILIDAD DE LA ACCIÓN DE RECLAMACIÓN DE FILIACIÓN. SENTENCIA SOBRE EL ALCANCE DE LA LEGITIMACIÓN PASIVA DE LA ACCIÓN DE RECLAMACIÓN INTENTADA POR EL HIJO (JUZGADO DE FAMILIA DE VALDIVIA, CORTE DE APELACIONES DE VALDIVIA)
}

\author{
Comentario de Susan Turner Saelzer
}

Valdivia, veinticinco de enero de dos mil siete.

VISTOS y OÍDOS:

PRIMERO: Que doña Elena del Carmen Aburto Martínez, dueña de casa, domiciliada en Claudio Arrau N ${ }^{\circ} 781$, El Bosque, San Bernardo, representada por su abogado don Mauricio Velásquez Guerra, interpuso demanda de reclamación de filiación en contra de don Manuel Hernán, Germán Vicente, Ernesto Waldemar, y Juan Carlos, todos Aburto Rodríguez, y en contra de doña Brígida Rodríguez Martínez, en su calidad de herederos de don Manuel Enrique Aburto Díaz. Funda su demanda en que conoció a su padre biológico don Manuel Aburto Díaz, en el año 1984, época en que ella tenía 35 años de edad, fecha desde la cual don Manuel tuvo siempre una actitud positiva hacia ella, ya que siempre supo de su existencia, pero por diferencias con su madre y por haber formado una nueva familia, nunca logró contactarla. Que desde aquella fecha comenzó a visitar a su padre y hermanos periódicamente. Ella fue recibida como una hermana más, presentándola a toda la familia y a la cónyuge de don Manuel como "la hija de don Manuel Enrique Aburto Díaz". Que a partir de ese momento, todos los veranos, comenzó a visitar a su padre, quien se encontraba casado con doña Brígida Rodríguez, con quien tuvo cuatro hijos: Manuel Hernán, Germán Vicente, Ernesto Waldemar, y Juan Carlos, todos Aburto Rodríguez.

Que toda la familia la recibió como una integrante más de ella, tanto es así que en año 1990 se comenzó la construcción de una casa habitación para la demandante, en el Fundo Lucatraro, lugar en el que vive casi toda la familia, y que hasta los días de hoy sirve de lugar de descanso a los miembros de la familia de la demandante.

Que al momento de conocer a su padre, ella no planteó que la reconociera legalmente, pues sólo se preocupó de compartir con él y la familia, sin pensar que dicha situación quedaría inconclusa, a pesar de haber compartido por más de veinte años como padre e hija.

Que la posesión notoria de su calidad de hija superó con creces los cinco años continuos establecidos en nuestra legislación, situación de hecho avalada por los demandados, que 
están de acuerdo en que se interponga la presente gestión, pues nunca han desconocido la calidad de hija de la demandante en relación con don Manuel Aburto Díaz, quien falleció el 5 de agosto de 2005, sin reconocerla legalmente.

En cuanto al derecho, la parte demandante señala que el artículo 195 del Código Civil posibilita la investigación de la paternidad, siendo este derecho "imprescriptible e irrenunciable"; que el artículo 198 indica que en los juicios de filiación, "la maternidad y la paternidad podrán establecerse mediante toda clase de pruebas, decretadas de oficio o a petición de parte”. Se funda además en lo dispuesto en los artículos 317 inciso $2^{\circ}, 205$ y 1097 del mismo Código. Agrega que privar a los hijos de la posibilidad de demandar a los herederos, no se compadece con el contexto de la ley, ya que uno de los principios fundamentales de la Ley $\mathrm{N}^{\circ} 19.585$ es reconocer a toda persona el derecho a la identidad, principio además consagrado en el artículo 18 de la Convención Americana sobre Derechos Humanos, plenamente vigente en el ámbito del Derecho de Familia, según lo prescribe el artículo $5^{\circ}$ de la Carta Fundamental, que le otorga rango constitucional.

SEGUNDO: Que los demandados se allanaron a la demanda, señalando que están de acuerdo con que la demandante es hija de don Manuel Aburto Díaz.

TERCERO: Que en la audiencia preparatoria celebrada el 16 de noviembre de 2006, se dictó la resolución que citó a audiencia de juicio, estableciéndose que el objeto de éste es determinar la filiación de la demandante.

CUARTO: Que según el artículo 315 del Código Civil, los fallos que declaran verdadera o falsa la maternidad o paternidad del hijo, valen, no sólo respecto de las personas que han intervenido en el juicio, sino respecto de todos. Sin embargo, para producir este efecto que la doctrina denomina "erga omnes", es necesario, según el artículo 316 del mismo Código, entre otros requisitos, que se hayan pronunciado contra legítimo contradictor. En este sentido, el artículo 317 dispone que legítimo contradictor en la cuestión de paternidad es el padre contra el hijo o el hijo contra el padre, siendo también legítimos contradictores los herederos del padre fallecido en contra de quienes el hijo podrá dirigir o continuar la acción y también los herederos del hijo fallecido cuando éstos se hagan cargo de la acción iniciada por él o decidan entablarla. Que por su parte, los artículos 206 y 207 del Código Civil, regulan los casos en que podrá entablarse la acción de reclamación de filiación, ya sea en contra de los herederos del padre, o bien por los herederos del hijo.

QUINTO: Que es del parecer de esta sentenciadora que si bien el artículo 317 inciso $2^{\circ}$ del Código Civil permite dirigir acciones de filiación en contra de los herederos del padre fallecido, dicha facultad está sólo circunscrita al caso especialmente regulado en el artículo 206 del Código Civil, aplicándose además el artículo 207 si el hijo también hubiere fallecido. En efecto, si el derecho a reclamar la filiación es imprescriptible, ¿por qué en el caso del hijo póstumo o si alguno de los padres fallece dentro de los ciento ochenta días siguientes al parto, el artículo 206 estableció un plazo, ya sea éste denomi- 
nado de prescripción o de caducidad? La respuesta a la interrogante anterior no es otra que la siguiente: porque el derecho a reclamar la filiación se extingue con la muerte, y sólo en el caso del artículo 206 la ley estableció una excepción.

SEXTO: Que en el presente caso, la demandante no es una hija póstuma, ni tampoco el supuesto padre falleció dentro de los ciento ochenta días siguientes al parto, razón por la cual rige la regla general, es decir, el derecho a reclamar la filiación se extinguió con la muerte del supuesto padre y por tanto los herederos de éste no son legítimos contradictores.

SÉPTIMO: Que independientemente de las discusiones que esta postura suscite en Derecho Comparado, a este Tribunal corresponde aplicar la ley, teniendo presente, a mayor abundamiento, que a la misma conclusión señalada en los dos motivos anteriores, llega la doctrina. Claudia Schmidt y Paulina Veloso ("La filiación en el nuevo derecho de familia”, LexisNexis, primera edición, año 2001) señalan que "en todo caso, la acción de reclamación se extingue con la muerte, salvo casos limitados” (página 133) "los herederos del padre fallecido son titulares pasivos sólo en los supuestos establecidos en la ley... a) que el hijo sea póstumo; b) que alguno de los padres fallezca dentro de los ciento ochenta días siguientes al parto" (página 188). En el mismo sentido, René Ramos Pazos (Derecho de familia Tomo 11 Editorial Jurídica de Chile, cuarta edición actualizada) señala que "El artículo 206 representa una innovación con respecto al anterior artículo 272, que exigía que aquel que pretendiera obtener judicialmente la calidad de hijo natural, debía intentar su demanda en vida del supuesto padre o madre" (página 405).

OCTAVO: Que la parte demandante cita además el artículo 1097 del Código Civil. Dicha norma se encuentra entre las normas relativas a las "asignaciones testamentarias", y esta sentenciadora desconoce si don Manuel Aburto Díaz testó antes de fallecer. Sin embargo, debe tenerse presente que la titularidad pasiva en una reclamación de filiación no puede considerarse como un bien, derecho u obligación "transmisible", en los términos de la citada disposición o del artículo 951 del Código Civil.

NOVENO: Que las materias relativas al estado civil son indisponibles para las partes, por lo que a pesar de que los demandados se allanaron a la demanda, ésta debe ser rechazada, resultando inoficioso pronunciarse sobre la prueba rendida para acreditar la posesión notoria del estado civil, atendidas las razones ya expresadas.

$\mathrm{Y}$, vistos, además lo dispuesto en los artículos $8 \mathrm{~N}^{\circ} 9$, y 55 y siguientes de la Ley 19.968; 315, 316 y 317 del Código Civil; y 144 del Código de Procedimiento Civil, se declara:

I. Que se rechaza la demanda de reclamación de filiación, interpuesta por doña Elena del Carmen Aburto Martínez, en contra de don Manuel Hernán, Germán Vicente, 
Ernesto Waldemar, y Juan Carlos, todos Aburto Rodríguez, y en contra de doña Brígida Rodríguez Martínez, en su calidad de herederos de don Manuel Enrique Aburto Díaz.

II. Que no se condena en costas a la demandante, por estimar que tuvo motivos plausibles para litigar.

Regístrese y archívese oportunamente, si no se apelare.

RIT C-1505-2006

Dictada por doña Alodia Prieto Góngora, Juez Suplente del Tribunal de Familia de Valdivia.

Valdivia, doce de marzo de dos mil siete.

\section{VISTOS:}

Se reproduce la sentencia en alzada, con excepción de los fundamentos quinto, sexto, séptimo, octavo y noveno. Y se tiene en su lugar y además presente:

1) Que del mérito de los antecedentes, documentos y testimonios aparejados al proceso, se desprende que la actora detentó más allá del término legal la posesión notoria de hija no matrimonial de don Manuel Aburto Díaz.

2) Que habiéndose deducido la acción de filiación contra los herederos, entendiendo que éstos son legítimos contradictores, y considerando el allanamiento a la pretensión de la demandante, se estima procedente acoger la demanda de fojas $1 \mathrm{y}$ siguientes. y vista las citas legales, en particular lo dispuesto por los artículos 195 y 317 del Código Civil, se resuelve:

SE REVOCA la sentencia apelada de veinticinco de enero de dos mil siete escrita de fojas 28 a 31, Y se declara que doña Elena del Carmen Aburto Martínez es hija no matrimonial de don Manuel Aburto Díaz, ordenándose efectuar las subinscripciones ante el Servicio de Registro Civil e Identificación que procediera.

Regístrese y devuélvase.

Rol N 137-2007.

Pronunciada por la Primera Sala, por el Ministro Sr. Mario Julio Kompatzki Contreras, Ministra Srta. Ruby Alvear Miranda y Abogada Integrante Sra. Helga Steffen Riedemann. 


\section{Comentario}

El tema sobre el que recaen las sentencias trascritas no es nuevo. Ellas reflejan los dos extremos argumentativos avalados por la doctrina nacional y por la jurisprudencia - no uniforme- de la Corte Suprema, y en esa medida, los fundamentos esgrimidos por los sentenciadores son absolutamente previsibles. Por otra parte, los hechos que dan lugar al juicio no presentan dificultades ni en cuanto a su verosimilitud ni en cuanto a su acreditación. ¿Qué interés puede revestir, entonces, un comentario sobre estos fallos? Considero que el interés está dado por el hecho de concentrar el caso al menos dos disputas cuya decisión marca un sistema normativo de acciones de filiación.

En efecto, a propósito de la determinación del sujeto pasivo de la acción de reclamación de filiación no matrimonial, el caso deja entrever distintas comprensiones sobre el alcance de la transmisibilidad de la acción: sólo puede transmitirse la faz activa de la misma, no así su aspecto pasivo, o, por el contrario, la transmisión comprende tanto su titularidad activa como pasiva; la transmisión sólo opera por disposición expresa de la ley, o, en cambio, constituye la regla general debiendo, por consiguiente, constar las excepciones en texto expreso. Por otra parte, el caso trasunta también diferentes concepciones sobre la disponibilidad de la acción de reclamación: improcedencia del allanamiento a la demanda en juicios de filiación o, al contrario, aplicación de las reglas procesales generales y por ende, aceptación del allanamiento del demandado.

Desde un punto de vista lógico, la secuencia de argumentos del fallo de segunda instancia debió partir por afirmar la transmisibilidad de la condición de sujeto pasivo de la acción a los herederos del supuesto padre (considerando $2^{\circ}$ ), para continuar con la posesión notoria de la calidad de hija que habría detentado la parte demandante respecto del causante, en vida de éste (considerando $1^{\circ}$ ). Sólo aceptando la primera es posible pronunciarse sobre la segunda, pues la posesión notoria constituye un medio de establecimiento de la filiación en el marco de un proceso judicial correctamente tramitado en cuanto a sus partes. En este sentido, la sentencia de primera instancia es acertada al declarar en el considerando noveno que "resulta inoficioso pronunciarse sobre la prueba rendida para acreditar la posesión notoria del estado civil” ya que antes se había pronunciado a favor de una interpretación restrictiva de la transmisibilidad de la acción de reclamación, en un doble sentido: tanto en relación con que ella sólo se referiría a la legitimación activa de la acción, es decir, a la hipótesis regulada en el artículo 207 CC (ratificada por lo prescrito en el artículo 317 inciso $2^{\circ}$, segunda frase), como en el entendido que sólo en los dos casos previstos por el artículo 206 estarían legitimados pasivamente los herederos del supuesto padre, casos a los que aludiría, a propósito del legítimo contradictor, la norma del artículo 317 inciso $2^{\circ}$, primera frase. Por consiguiente, al ser improcedente en el caso la acción deducida por falta de legitimación pasiva de los demandados al faltar alguna de las situaciones del artículo 206, no necesitaba el juez a quo pronunciarse acerca de la posesión notoria de estado.

La solución asumida por la sentencia de alzada coincide con la expuesta por la Corte Suprema en fallo de 21 de septiembre de 2006 (rol 3249-2005) y resulta abiertamente favorable al hijo en la medida que la muerte del padre o madre no suponen, 
salvo excepcionalmente, la imposibilidad de realización de su derecho a la identidad. Sin embargo, nuestro máximo tribunal había sostenido anteriormente la tesis contraria (sentencia de fecha 2 de noviembre de 2004 en causa rol 2820-2004, cuyo voto de minoría es recogido por el Prof. Ramos Pazos en la quinta edición actualizada de su obra Derecho de Familia, T. II, p. 402), que, tal como el presente fallo de primera instancia, afirmaba que la acción de reclamación sólo se transmite en su faz pasiva a los herederos en los dos casos descritos en el artículo 206 y por el tiempo allí señalado, descartándose cualquier otra hipótesis en que pudiesen ser demandados los herederos del supuesto padre o madre fallecidos.

El escueto fallo de segunda instancia da por acreditada la posesión notoria del estado civil de hija de la demandante respecto del causante cuyos herederos fueron demandados. Es decir, los sentenciadores parten de la base que el padre fallecido dio el nombre y trato, y consintió en la fama de hija de la demandante pero que, pudiendo haberla reconocido como tal, no lo hizo. De esta manera, la posesión notoria muda de medio correctivo a la búsqueda irrestricta de la verdad biológica -rol atribuido a ella por el artículo 201 inciso $1^{\circ}-$ a medio sustitutivo del reconocimiento.

En cuanto a la disponibilidad de la acción, el fallo de alzada considera como una reafirmación de la existencia de la posesión notoria de estado el allanamiento de los demandados, razonamiento que conlleva una fuerte restricción al carácter indisponible de las acciones de estado fundado en los artículos 2450 CC; 262 CPC; 57 LMC, entre otras disposiciones. Pero aún admitiendo la procedencia del allanamiento a la demanda, su efecto natural consistiría en la omisión de la etapa de prueba en el juicio. Cabe preguntarse, entonces, cómo llegó a acreditarse la posesión notoria de la calidad de hija de la demandante. 